Tohoku J. Exp. Med., 2014, 232, 9-19

\title{
CD44 Expression Is Predictive of Poor Prognosis in Pharyngolaryngeal Cancer: Systematic Review and Meta-Analysis
}

\author{
Liang Chai, ${ }_{1}^{1}$ Hongyan Liu, ${ }^{1}$ Zhili Zhang, ${ }^{1}$ Feng Wang, ${ }^{1}$ Qingying Wang, ${ }^{1}$ \\ Shuihong Zhou ${ }^{1}$ and Shenqing Wang ${ }^{1}$ \\ ${ }^{1}$ Department of Otorhinolaryngology, First Affiliated Hospital, Medical School, Zhejiang University, Hangzhou, \\ P.R. China
}

\begin{abstract}
Pharyngolaryngeal cancer is one of the most common head and neck cancer worldwide, and the early diagnosis and prognosis prediction are still difficult because of lacking in reliable cell markers. Although the expression of CD44 has been reported to correlate with poor prognosis of pharyngolaryngeal cancer in most literatures, some controversies still exist. Since the limited patient numbers within independent studies, here we performed a meta-analysis to clarify the correlations between CD44 expression and clinicopathological features and prognosis in pharyngolaryngeal cancer. A search of PubMed, ISI Web of Science and China National Knowledge Infrastructure databases (up to June 2013) was performed. Nineteen studies with 1,405 patients met the inclusion criteria. The expression of pan-CD44, including all variant isoforms, was detected in 58.0\% (14.1-79.2\%) specimens, while CD44-v6 (variant isoform 6 of CD44) was expressed in $54.8 \%(12-79.2 \%)$. In pooled analysis, CD44 expression was significantly associated with larger tumor size (T category, RR (relative risk) $=1.21,95 \% \mathrm{Cl}: 1.01-1.46$ ), lymph nodes metastasis ( $\mathrm{N}$ category, $\mathrm{RR}=1.94,95 \% \mathrm{Cl}$ : 1.38-2.73) and poor prognosis [3-year overall survival (OS): $\mathrm{RR}=0.70,95 \% \mathrm{Cl}: 0.53-0.91 ; 5$-year OS: $\mathrm{RR}=0.66,95 \% \mathrm{Cl}: 0.66-0.94]$. In the stratified analysis of CD44 isoforms, high expression of CD44-v6 was related with a poor 5-year OS rate $(\mathrm{RR}=0.53,95 \% \mathrm{Cl}$ : 0.37 077). We propose that CD44 expression is associated with tumor size, lymph node metastasis, and poor prognosis in pharyngolaryngeal cancer patients.
\end{abstract}

Keywords: CD44; laryngeal cancer; meta-analysis; pharyngeal cancer; prognosis

Tohoku J. Exp. Med., 2014 January, 232 (1), 9-19. (C) 2014 Tohoku University Medical Press

\section{Introduction}

Head and neck squamous cell carcinoma (HNSCC) is common worldwide, and technological improvements have increased treatments of HNSCC patients with minimally invasive surgery (Murata et al. 2011; Zhu et al. 2012). Instead of laryngopharyngectomy, which would severely affect the quality of life, radiotherapy and laser therapy have been applied widely. However, the lack of available markers to distinguish the patients with an aggressive form of HNSCC from those with a better outcome has been an obstacle for doctors in selecting the appropriate treatment.

In recent years, a number of cell surface markers were found to indicate a small group of cancer cells, referred as cancer stem cells (CSCs), which are responsible for tumor initiation, progression, metastasis and drug resistance (Nguyen et al. 2012). Many researchers have reported that high expression of these markers indicates bad clinical features and poor prognosis (Lee et al. 2009; Wang et al. 2012;
Ni et al. 2013). The CSC hypothesis also has been connected to pharyngolaryngeal cancer (Faber et al. 2011; Janisiewicz et al. 2012), and CD44 was one of the most reported CSC markers.

The CD44 is a type I transmembrane glycoprotein with seven extracellular domains, a transmembrane domain and a cytoplasmic domain (van der Windt et al. 2011). The CD44 gene is expressed on many cell types, including lymphocytes, epithelial cells and mesodermal cells (Fox et al. 1994). Also it is located on chromosome 11p13 and consists of at least 20 exons (Rodrigo et al. 2002). Among the exons, ten exons are constitutively expressed to produce a 85- to $90-\mathrm{Kd}$ isoform named as CD44 standard form (CD44s), whereas other isoforms called CD44 variants $(\mathrm{CD} 44 \mathrm{v})$, are generated by alternatively spliced transcripts (Zoller 2011). Up to date, CD44v6 was the most reported isoform in pharyngolaryngeal cancer (Song et al. 1999; Wang et al. 2000; Kawano et al. 2004; Andratschke et al. 2005; Staibano et al. 2007; Huang et al. 2007; Lu et al.

Received October 2, 2013; revised and accepted December 25, 2013. Published online January 16, 2014; doi: 10.1620/tjem.232.9. Correspondence: Liang Chai, First Affiliated Hospital, Medical School, Zhejiang University, Hangzhou 310003, P.R. China.

e-mail: davenc@163.com 
2008; Guo et al. 2009; Gao 2009).

The prognostic value of CD44 for patients with cancer has been reported in various solid tumors, including colon, lung, and breast cancer (Leung et al. 2010; Su et al. 2011; Brown et al. 2011). With respect to pharyngolaryngeal cancer, the relationships between CD44 and clinicopathological features and prognosis were still controversial mainly because of the limited patient numbers of independent reports (Xu et al. 2003; Esteban et al. 2005). Here we performed a systematic review of the published studies and aimed to investigate the prediction value of CD44 in clinical features and prognosis of pharyngolaryngeal cancer.

\section{Materials and Methods}

\section{Search Strategy}

We performed a comprehensive literature search of the PubMed, ISI Web of Science and China National Knowledge Infrastructure (CNKI) databases up to June 2013. The search terms included 'CD44'; 'larynx or laryngeal'; 'pharynx, nasopharynx, oralpharynx, hypopharynx or pharyngeal' with 'cancer'; 'neoplasm'; or 'carcinoma'. The titles and abstracts of potential references were manually examined to exclude irrelevant studies; the remaining articles within the topic of interest were reviewed for further study.

\section{Selection Criteria}

The studies included in this meta-analysis were randomized control studies (RCTs) or observational studies (case-control or cohort) that evaluated the association between CD44 expression and the clinical features or prognosis of pharyngolaryngeal cancer. Studies were eligible if they met the following criteria: (a) aimed at laryngeal or pharyngeal squamous cell carcinoma; (b) defined a CD44-positive group by immunohistochemistry, with the pan-CD44 antibody or the CD44 variant specific antibody; (c) described correlations between $\mathrm{CD} 44$, clinicopathological features and survival outcome (disease free survival or overall survival); (d) written in English or Chinese. Articles were excluded from the analyses based on the following criteria: (a) review articles or letters, (b) insufficient data to determine the relative risk (RR) and confidence interval (CI), or (c) the full text could not be found.

According to the review checklist provided by the Dutch Cochrane Centre (Stroup et al. 2000) and with the aim to control the quality of this meta-analysis, we grossly assessed the quality of all the included studies with seven key points: (a) a clear definition of the study population and origin of country, (b) a clear definition of the type of carcinoma, (c) a clear definition of the study design, (d) a clear definition of the outcome assessment, (e) a clear definition of the cut-off value of CD44 expression, (f) a clear definition of the method of CD44 assessment, and (g) a sufficient time of follow-up.

\section{Data Extraction}

All of the data of the eligible studies were extracted by two independent reviewers, with a predefined table (Table 1). The data tables were generated to extract all the relevant data from the texts, tables and figures, including: author, year, country, patient number, detection method, information of antibody applied, duration of follow-up, $\mathrm{T}$ category, $\mathrm{N}$ category, distant metastasis, positive rates of pan-CD44 (all CD44 isoforms) or CD44 isoforms (CD44s, CD44v6, $\mathrm{CD} 44 \mathrm{v} 3$ ) expression, and the disease-free (DFS) and overall survival
(OS) rates. Because almost articles presented survival data with a Kaplan-Meier curve, the GetData Graph Digitizer 2.24 (http:/get data-graph-digitizer.com/) was used to extract data.

Since the cut-off value for CD44 expression varied among these studies, we defined the CD44 positive group based on the original articles. A number of studies present 3-year survival outcome data, whereas others described 5-year survival outcome, here we both analyzed the 3- and 5-year overall survival rate.

\section{Statistical Analysis}

The statistical analysis was performed according to the guidelines proposed by the Meta-Analysis of Observational Studies in Epidemiology group. The RR with a 95\% CI was calculated with Review Manager 4.2. The heterogeneity among studies was measured using the $\mathrm{Q}$ and $\mathrm{I}^{2}$ tests. A fixed or random model was used depending on the heterogeneity analysis. The potential for publication bias was assessed using the Begg rank correlation method and the Egger weighted regression method (software stata 11.0). A $P$ value $<0.05$ was considered statistically significant. All of the $P$ values were two-tailed. The stratified analyses were performed concerning the specific organs, geographical locations, CD44 variant (CD44-v6), sample size and follow-up duration.

\section{Results}

\section{Search Results}

A total of 208 articles were initially retrieved according to the search strategy described above. From the title and abstract review, 140 of the articles were excluded because they were a non-human experiment, a non-laryngeal or pharyngeal cancer-related study, or a non-original article (e.g., a review or letter). Of the remaining articles, 49 were excluded because they did not provide the original clinicopathological data. Finally, nineteen studies with 1,405 participants were included in the meta-analysis, which evaluated the expression of CD44 and risk of cancer progression by immunohistochemical staining (Fig. 1).

\section{Study Characteristics}

The features of the 19 eligible studies are listed in Table 1; 1 study was from each of the following countries: Spain (Esteban et al. 2005), Turkey (Yuce et al. 2011), Italy (Staibano et al. 2007), Finland (Kokko et al. 2011), and the USA (Janisiewicz et al. 2012), two studies were from Japan (Kawano et al. 2004; Uwa et al. 2011), and 12 were from China (Song et al. 1999; Wang et al. 2000; Zhao et al. 2003; $\mathrm{Xu}$ et al. 2003; Wang et al. 2004; Qiu et al. 2006; Huang et al. 2007; Lu et al. 2008; Ma et al. 2009; Gao 2009; Guo et al. 2009; Lu et al. 2011). Three studies focused on pharyngeal cancer, 14 focused on laryngeal cancer, and 2 studied both laryngeal and pharyngeal cancer. A total of 1,405 patients with a median of 58 patients (from 40 to 154) per study were included. The tumor grade and TNM stage (tumor size, lymph node metastaisis and distant metastasis) were presented in 9 and 16 studies, respectively. 58.0\% (14.1-79.2\%) of all included pharyngolaryngeal cancer specimens were found CD44 positive expression, while CD44-v6 (variant isoform 6 of CD44) was expressed in 


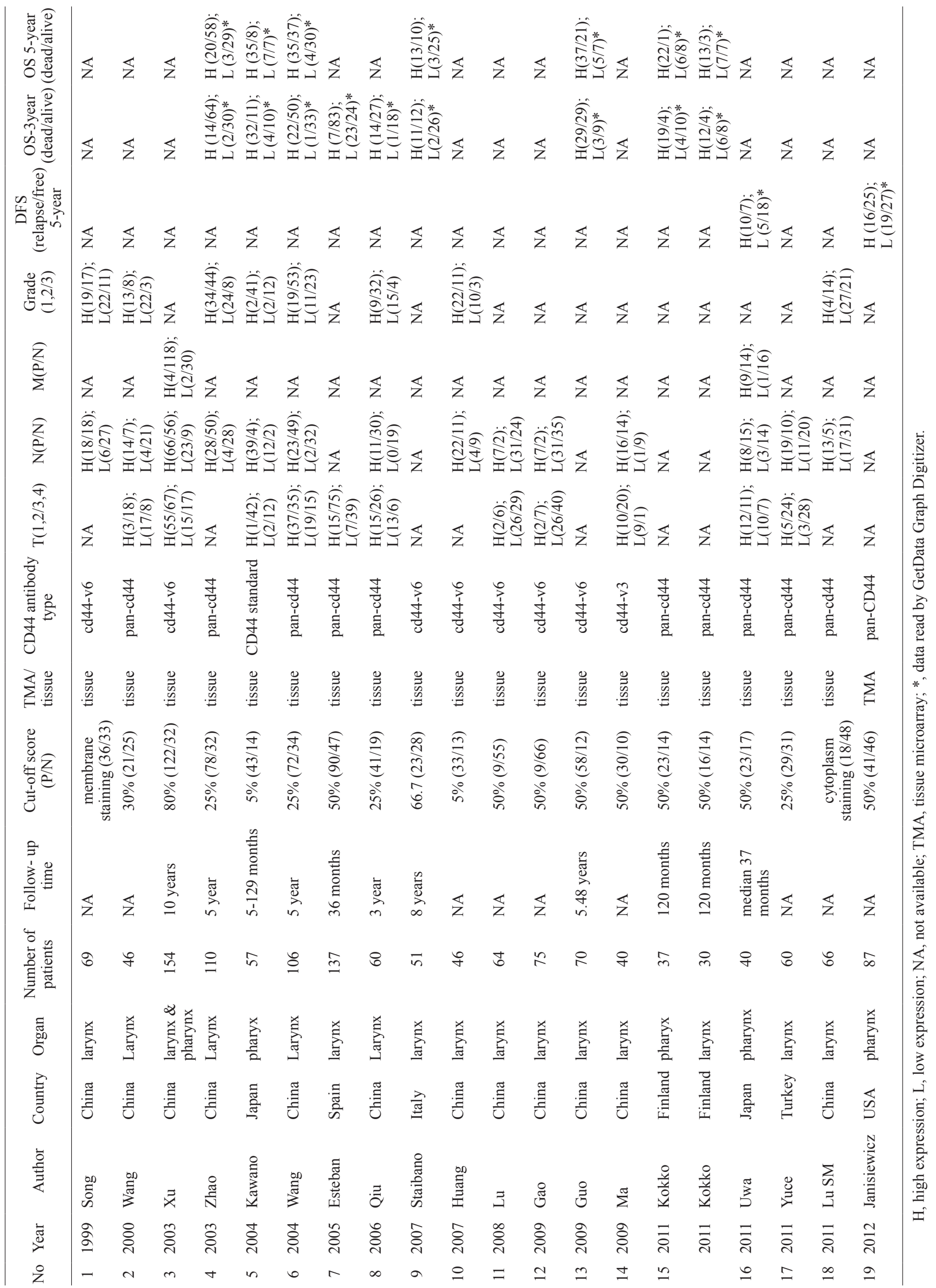




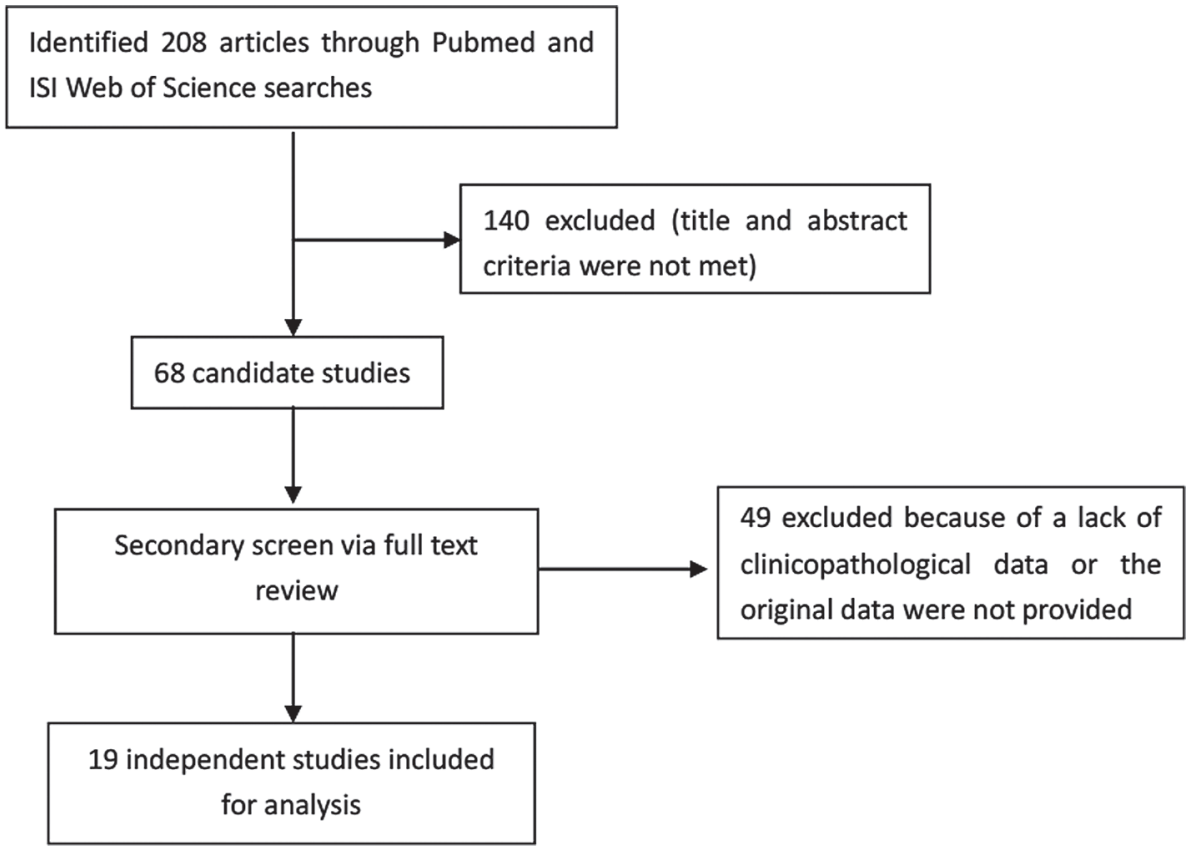

Fig. 1. Flow chart for the selection of the included articles.

$54.8 \%(12-79.2 \%)$ specimens, and a difference between patients in Asia $(56.8 \%)$ and Europe $(55.2 \%)$ was not found. The overall survival rate was reported in 8 studies. Regarding the immunochemistry assay, all studies used formalin-fixed samples, 11 studies used the anti-Pan-CD44 antibody, 7 studies used the anti-CD44-v6 antibody, 1 study used the anti-CD44-v3 antibody, and 1 study used the antiCD44s antibody (Tables 1 and 4); the stratified analysis was performed based on the anti-pan-CD44 and anti-CD44-v6 antibodies. None of the patients received neo-adjuvant radiotherapy or chemotherapy prior to surgery. The patients in the study of Kawano et al. (2004) received surgery and radiotherapy after diagnosis, and the patients of other studies were treated with curative surgery.

\section{Correlation of CD44 to clinical features}

The results of correlation between CD44 and clinical features were presented in Table 2. The overall analysis suggested that CD44 correlated more with the advanced $\mathrm{T}$ category $(\mathrm{RR}=1.21,95 \% \mathrm{CI}: 1.01-1.46), \mathrm{N}$-positive patients $(\mathrm{RR}=1.94,95 \% \mathrm{CI}: 1.38-2.73)$ and higher tumor grade $(\mathrm{RR}=1.68,95 \% \mathrm{CI}: 1.13-2.52)$. In the subgroup analysis divided on cancer types, similar results were retrieved in laryngeal cancer; the CD44 over-expression was related with a higher $\mathrm{T} 3$ and $\mathrm{T} 4$ category $(\mathrm{RR}=1.33$, $95 \%$ CI: 1.01-1.76), worse $\mathrm{N}$ category $(\mathrm{RR}=2.64,95 \% \mathrm{CI}$ : 1.98-3.06), tumor grade $(\mathrm{RR}=1.95,95 \% \mathrm{CI}: 1.18-3.21$ ) and 5 -year OS rate $(\mathrm{RR}=0.62,95 \% \mathrm{CI}: 0.47-0.83)$. In pharyngeal cancer specifically, the CD44 expression was only found to be associated with worse 3-year OS rate (RR $=0.31,95 \%$ CI: 0.18-0.52), which might be explained by a small number of studies. Then we stratified the data by the geographic area, antibody used, follow-up time and sample size. The studies in Asia showed that CD44 expression was related with $\mathrm{T} 3$ and $\mathrm{T} 4$ category patients (pool $\mathrm{RR}=1.39$, 95\%CI: 1.17-1.64; laryngeal cancer: $\mathrm{RR}=1.60,95 \% \mathrm{CI}$ : 1.14-2.25) and a N-positive status (pool RR $=1.97,95 \%$ CI: 1.37-2.84; laryngeal cancer: $\mathrm{RR}=2.57,95 \% \mathrm{CI}$ : $2.03-$ 3.26). In Europe and the USA, the studies were composed exclusively of laryngeal cancer patients, and the results showed that CD44 expression was related to advanced $\mathrm{N}$ category patients $(\mathrm{RR}=1.85,95 \% \mathrm{CI}: 1.07-3.18)$. The subgroup analysis was performed according to the specific antibody used. The studies with pan-CD44 antibody (detect all CD44 isoforms) revealed that high expression of CD44 correlated with a positive $\mathrm{N}$ category (pharyngolaryngeal cancer: $\mathrm{RR}=2.60,95 \% \mathrm{CI}: 1.96-3.45$; laryngeal cancer: $\mathrm{RR}=2.32,95 \% \mathrm{CI}: 1.73-3.11)$ and advanced tumor grade (pharyngolaryngeal cancer: $\mathrm{RR}=1.95,95 \% \mathrm{CI}: 1.18-3.21$; laryngeal cancer: $\mathrm{RR}=1.95,95 \% \mathrm{CI}: 1.18-3.21$ ) in overall and laryngeal cancer. In contrast, high expression of CD44-v6 was related with a positive $\mathrm{N}$ category in laryngeal cancer $(\mathrm{RR}=1.92,95 \% \mathrm{CI}: 1.39-2.64)$. The studies with a shorter follow-up time $(<68.5$ months) did not demonstrate an association between the CD44 expression and the clinicopathological features, whereas longer follow-up times ( $\geq 68.5$ months) showed that CD44 was related to a positive $\mathrm{N}$ category $(\mathrm{RR}=1.87,95 \% \mathrm{CI}: 1.28-2.74)$ and higher tumor grade $(\mathrm{RR}=1.89,95 \% \mathrm{CI}$ : 1.29-2.77). A similar result was found in the subgroup analysis based on sample size; only studies with a larger sample size related $\mathrm{CD} 44$ with a positive $\mathrm{N}$ category $(\mathrm{RR}=1.87,95 \% \mathrm{CI}$ : $1.25-2.78)$ and higher tumor grade $(\mathrm{RR}=1.83,95 \% \mathrm{CI}$ : 1.08-3.08). 


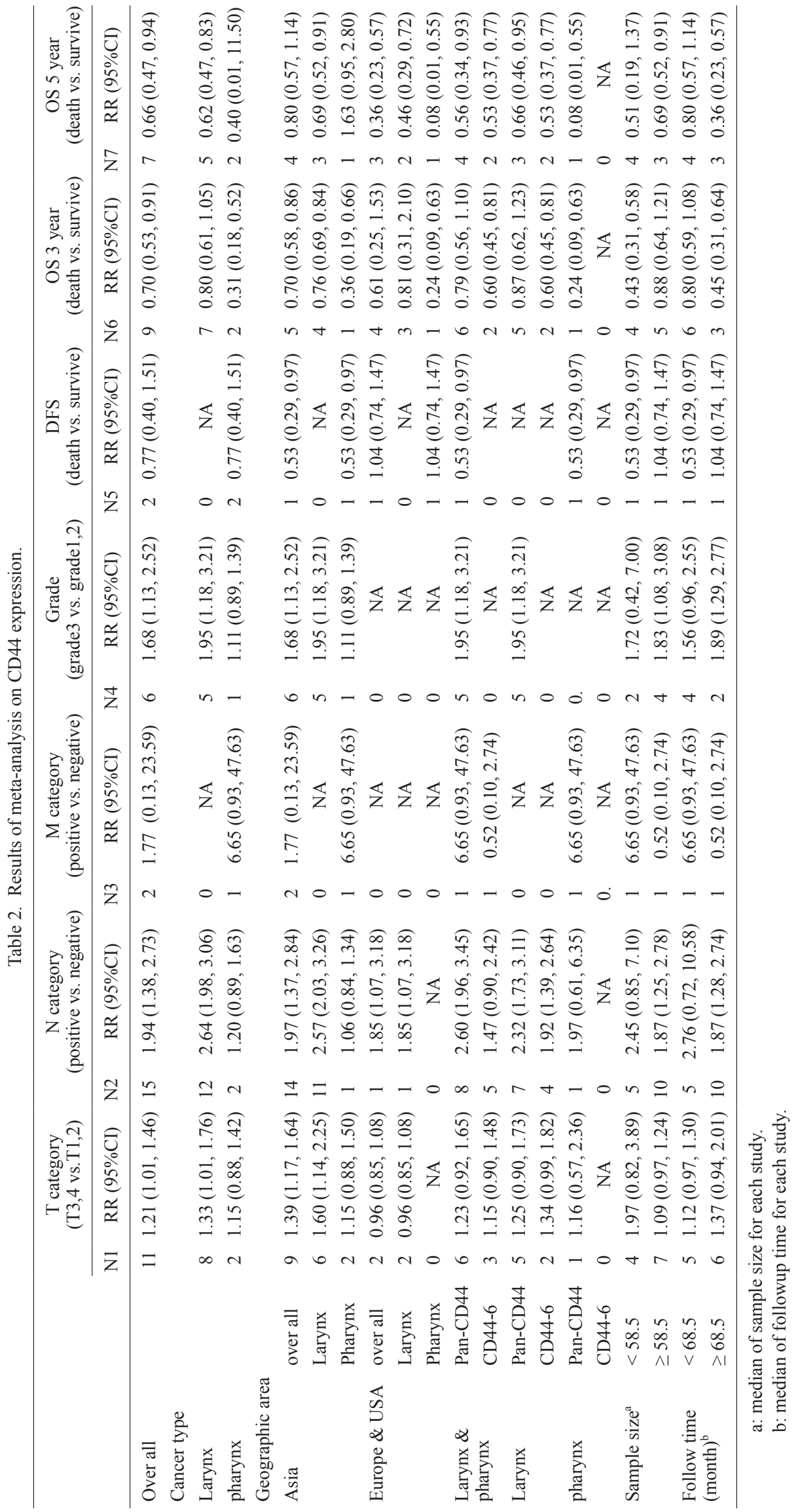




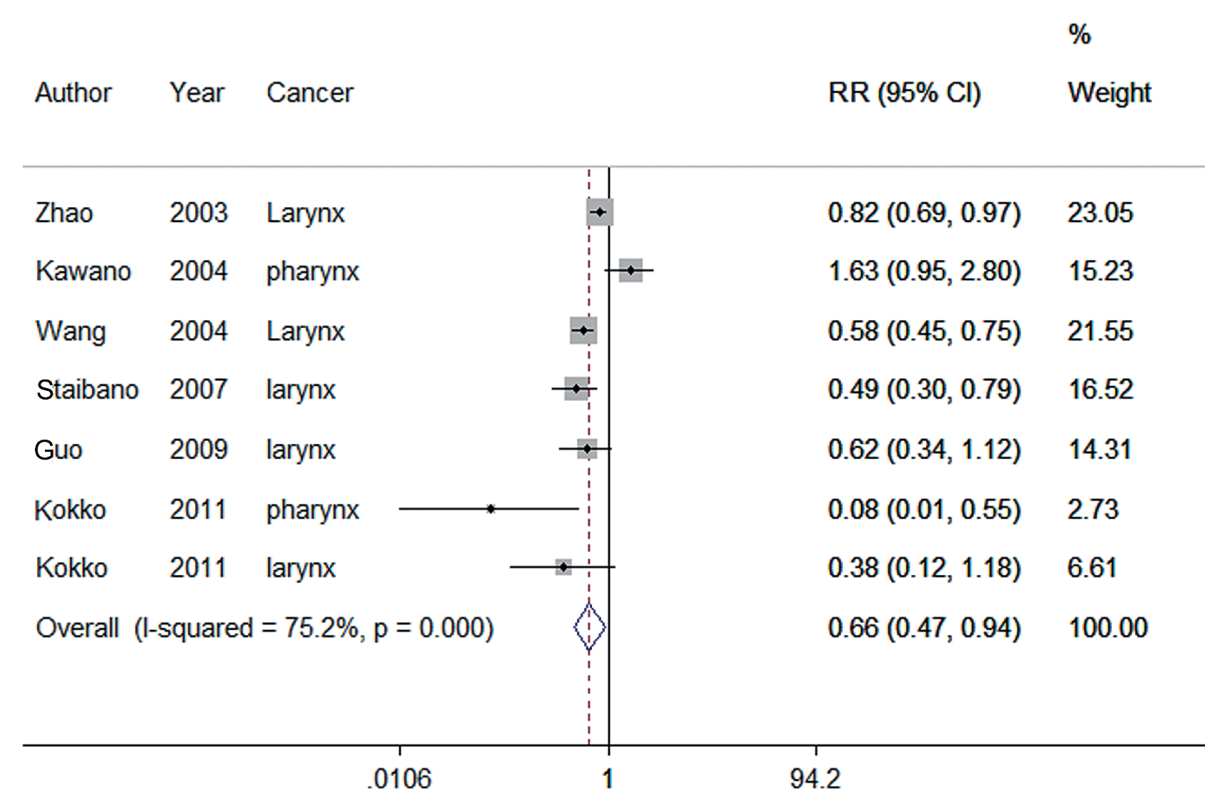

Fig. 2. CD44 expression and 5-year OS rate of pharyngolaryngeal cancer patients.

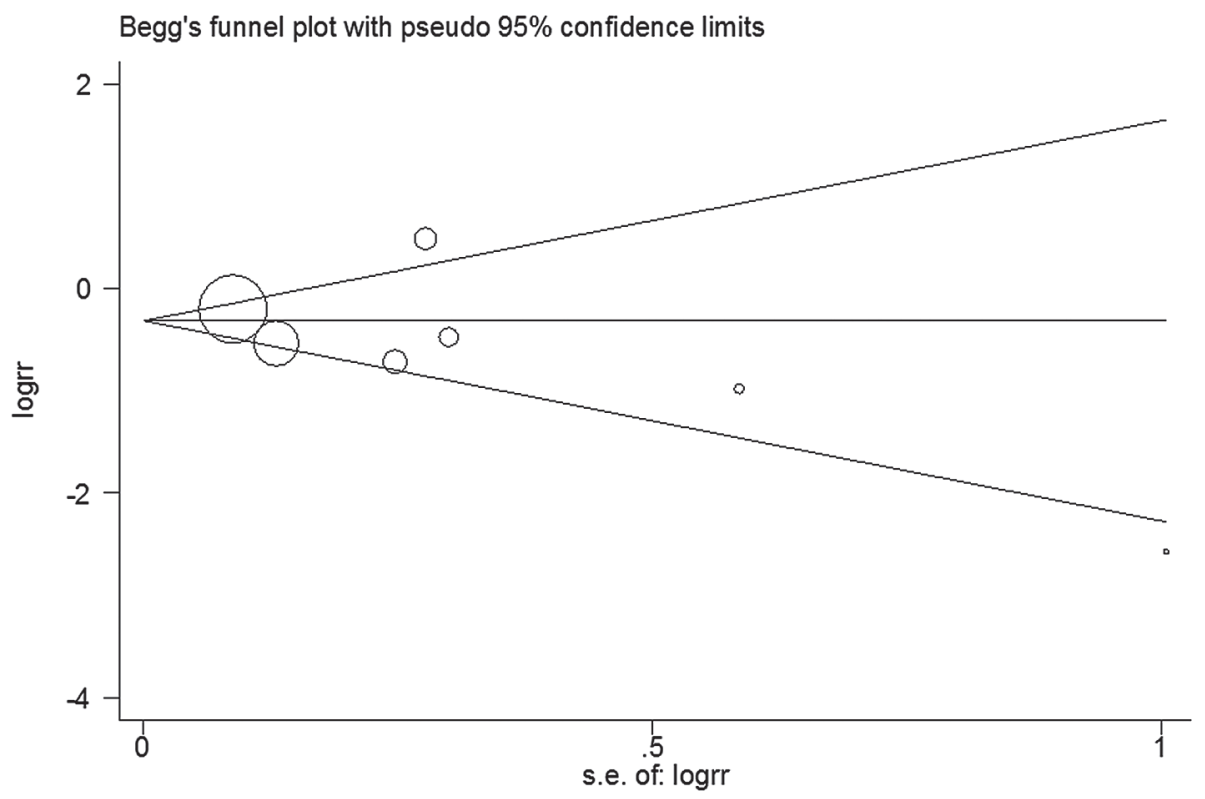

Fig. 3. Begg's test results of pharyngolaryngeal cancer patients' 5-year OS rate.

CD44 expression and overall survival rate

The 3-year and 5-year overall survival rate was extracted from 8 studies and 6 studies, respectively, whereas the disease free survival rate was reported in 2 studies (Table 1). The pooled 3-year overall survival rates of CD44-positive and CD44-negative patients were $66.1 \%$ $(255 / 386)$ and $78.7 \%(159 / 202)$, respectively, whereas the 5 -year overall survival rates were $45.9 \%(117 / 255)$ and $77.9 \%$ (106/136), respectively (Table 1). The pooled analysis showed that a high expression of CD44 indicated a worse OS rate (3-year OS: RR $=0.70,95 \%$ CI: 0.53-0.91; 5-year OS: RR $=0.66,95 \%$ CI: 0.66-0.94; Fig. 2). CD44 over-expression was related to poor prognosis in laryngeal cancer (5-year OS: RR $=0.62,95 \%$ CI: 0.47-0.83, Table 2) and pharyngeal cancer (3-year OS: RR $=0.31,95 \% \mathrm{CI}$ : $0.18-0.52$, Table 2). With the stratified analysis based on the specific antibody, both studies use pan-CD44 or CD44-v6 antibody were found correlations of CD44 expression and worse 5-year OS rate in pharyngolaryngeal cancer patients (pan-CD44: $\mathrm{RR}=0.56,95 \% \mathrm{CI}$ : 0.34-0.93; CD44-v6: $\mathrm{RR}=0.53,95 \%$ CI: $0.37-0.77$, Table 2) and in laryngeal cancer patients (pan-CD44: $\mathrm{RR}=0.66,95 \% \mathrm{CI}$ : 0.46-0.95; CD44-v6: RR $=0.53$, 95\% CI: 0.37-0.77, Table 2). 
Table 3. Heterogeneity test and publication bias analyses among studies.

\begin{tabular}{|c|c|c|c|c|c|c|c|c|c|c|c|c|c|c|c|c|c|}
\hline & & \multicolumn{4}{|c|}{$\begin{array}{c}\text { T category } \\
(\mathrm{T} 3,4 \text { vs. T1,2) }\end{array}$} & \multicolumn{4}{|c|}{$\begin{array}{c}\mathrm{N} \text { category } \\
\text { (positive vs. negative) }\end{array}$} & \multicolumn{4}{|c|}{$\begin{array}{c}\text { M category } \\
\text { (positive vs. negative) }\end{array}$} & \multicolumn{4}{|c|}{$\begin{array}{c}\text { Grade } \\
\text { (grade } 3 \text { vs. grade 1,2) }\end{array}$} \\
\hline & & \multicolumn{2}{|c|}{ Heterogeneity } & \multicolumn{2}{|c|}{$\begin{array}{l}\text { Publication } \\
\text { bias }\end{array}$} & \multicolumn{2}{|c|}{ Heterogeneity } & \multicolumn{2}{|c|}{$\begin{array}{l}\text { Publication } \\
\text { bias }\end{array}$} & \multicolumn{2}{|c|}{ Heterogeneity } & \multicolumn{2}{|c|}{$\begin{array}{l}\text { Publication } \\
\text { bias }\end{array}$} & \multicolumn{2}{|c|}{ Heterogeneity } & \multicolumn{2}{|c|}{$\begin{array}{l}\text { Publication } \\
\text { bias }\end{array}$} \\
\hline & & $P^{\mathrm{a}}$ & $\mathrm{I}^{2}(\%)^{\mathrm{b}}$ & $P^{\mathrm{c}}$ & $P^{\mathrm{d}}$ & $P^{\mathrm{a}}$ & $I^{2}(\%)^{b}$ & $P^{\mathrm{c}}$ & $P^{\mathrm{d}}$ & $P^{\mathrm{a}}$ & $\mathrm{I}^{2}(\%)^{\mathrm{b}}$ & $P^{\mathrm{c}}$ & $P^{\mathrm{d}}$ & $P^{\mathrm{a}}$ & $I^{2}(\%)^{b}$ & $P^{\mathrm{c}}$ & $P^{\mathrm{d}}$ \\
\hline \multicolumn{2}{|l|}{ Over all } & 0.002 & 64 & 0.013 & 0.003 & 0 & 80.3 & 0.042 & 0 & 0.044 & 75.4 & 1 & 0 & 0 & 79.5 & 0.133 & 0.006 \\
\hline \multicolumn{18}{|l|}{ Cancer type } \\
\hline \multicolumn{2}{|l|}{ Larynx } & 0 & 77.1 & 0.019 & 0.003 & 0.078 & 39.4 & 0.003 & 0 & NA & NA & NA & NA & 0.003 & 75.3 & 0.221 & 0.027 \\
\hline \multicolumn{2}{|l|}{ Pharynx } & 0.949 & 0 & 1 & NA & 0.173 & 46 & 1 & NA & 0 & NA & NA & NA & NA & 0 & NA & NA \\
\hline \multicolumn{18}{|c|}{ Geographic area } \\
\hline \multirow[t]{3}{*}{ Asia } & over all & 0.051 & 48.3 & 0.048 & 0.031 & 0 & 81.6 & 0.055 & 0 & 0.044 & 75.4 & 1 & 0 & 0 & 79.5 & 0.133 & 0.006 \\
\hline & Larynx & 0.067 & 51.5 & 0.133 & 0.059 & 0.04 & 47.4 & 0.004 & 0 & NA & NA & NA & NA & 0.003 & 75.3 & 0.221 & 0.027 \\
\hline & pharynx & 0.949 & 0 & 1 & NA & NA & 0 & NA & NA & NA & NA & NA & NA & NA & 0 & NA & NA \\
\hline \multirow[t]{3}{*}{ Europe } & over all & 0.587 & 0 & 1 & NA & NA & 0 & NA & NA & NA & NA & NA & NA & NA & NA & NA & NA \\
\hline & Larynx & 0.587 & 0 & 1 & NA & NA & 0 & NA & NA & NA & NA & NA & NA & NA & NA & NA & NA \\
\hline & pharynx & NA & NA & NA & NA & NA & NA & NA & NA & NA & NA & NA & NA & NA & NA & NA & NA \\
\hline \multirow[t]{2}{*}{ Larynx } & Pan-CD44 & 0 & 80.3 & 0.221 & 0.071 & 0.324 & 13.8 & 0.293 & 0.003 & NA & NA & NA & NA & 0.003 & 75.3 & 0.221 & 0.027 \\
\hline & CD44-6 & 0.744 & 0 & 1 & NA & 0.299 & 18.4 & 0.308 & 0.111 & NA & NA & NA & NA & NA & NA & NA & NA \\
\hline \multirow{2}{*}{$\begin{array}{l}\text { Larynx \& } \\
\text { pharynx }\end{array}$} & Pan-CD44 & 0.001 & 75.3 & 0.26 & 0.074 & 0.446 & 0 & 0.216 & 0.013 & NA & NA & NA & NA & 0.003 & 75.3 & 0.221 & 0.027 \\
\hline & CD44-6 & 0.501 & 0 & 0.296 & 0.252 & 0 & 80.8 & 0.221 & 0.039 & NA & 0 & NA & NA & NA & NA & NA & NA \\
\hline \multirow[t]{2}{*}{ Pharynx } & Pan-CD44 & NA & 0 & NA & NA & NA & 0 & NA & NA & NA & NA & NA & NA & NA & NA & NA & NA \\
\hline & CD44-6 & NA & NA & NA & NA & NA & 0 & NA & NA & NA & NA & NA & NA & NA & NA & NA & NA \\
\hline \multirow[t]{2}{*}{ Sample size ${ }^{a}$} & $<58.5$ & 0 & 83.6 & 0.734 & 0.233 & 0 & 87.7 & 0.462 & 0.021 & NA & NA & NA & NA & 0.019 & 81.8 & 1 & NA \\
\hline & $\geq 58.5$ & 0.146 & 37 & 0.016 & 0.014 & 0 & 79.4 & 0.04 & 0.003 & NA & NA & NA & NA & 0.003 & 78.5 & 0.089 & 0.037 \\
\hline \multirow{2}{*}{$\begin{array}{l}\text { Follow time } \\
\text { (month) }^{\mathrm{b}}\end{array}$} & $<68.5$ & 0.229 & 28.9 & 0.462 & 0.146 & 0 & 89.1 & 0.462 & 0.011 & NA & NA & NA & NA & 0 & 83.7 & 0.089 & 0.017 \\
\hline & $\geq 68.5$ & 0 & 77.7 & 0.024 & 0.014 & 0 & 79.3 & 0.009 & 0.001 & NA & NA & NA & NA & 0.321 & 0 & 1 & NA \\
\hline
\end{tabular}

NA, not available.

${ }^{a} P$ for heterogeneity within each subgroup.

${ }^{b}$ Proportion of between-study heterogeneity accounting for total heterogeneity.

' $P$ values of Begg's test.

d $P$ values of Egger's test.

\section{Publication Bias}

Heterogeneity testing and publication bias analyses were performed among the studies to evaluate the influence of individual studies on the summary OS rate. The results indicated no publication bias for the 3-year and 5-year OS rates regardless of the pooled analysis or stratified analysis (Table 3). The funnel plot was illustrated to assess the publication bias of 5-year OS of the included studies, and the funnel plots were almost symmetrical (Fig. 3).

\section{Discussion}

Although the treatment for head and neck cancer has improved rapidly, it is still the sixth most common cancer worldwide, predominantly because it is typically difficult to diagnose at early stages (Siegel et al. 2012). Moreover, the morbidity of head and neck cancer is growing in China, especially the laryngeal cancer in north China and pharyngeal cancer in south China. Except for the extension of people's age and the improvement of examination methods, the increasing morbidity should contribute to the increasing smoking population and aggravating air pollution (ML and O 2010).

The histopathological type and developmental origin among head and neck cancers (oral, pharynx and larynx) are highly homologous, and $90 \%$ of the tumors in the head and neck are squamous-cell carcinomas, which present as aggressive and recurrent malignancies (Kokko et al. 2011). In this meta-analysis, with reference to the clinicopathological parameters, CD44 was correlated with larger tumor size, positive $\mathrm{N}$ category and advanced tumor grade in pharyngolaryngeal cancer. Besides, CD44 expression was shown to predict a poor prognosis. In our analysis, CD44 expression was related to worse OS rates in both laryngeal and pharyngeal cancer. The $\mathrm{T}$ and $\mathrm{N}$ categories were not found to have a significant association with pharyngeal cancer, which might be explained by the limited number of studies. Because the CD44 family is composed of many variants, we examined the independent predictive value of pan-CD44 and CD44-v6 and found that they were associated with a poor 5-year OS; only pan-CD44 expression was 
Table 3. Continued.

\begin{tabular}{|c|c|c|c|c|c|c|c|c|c|c|c|c|c|}
\hline & & \multicolumn{4}{|c|}{$\begin{array}{c}\text { DFS } \\
\text { (death vs. survive) }\end{array}$} & \multicolumn{4}{|c|}{$\begin{array}{c}\text { OS } 3 \text { years } \\
\text { (death vs. survive) }\end{array}$} & \multicolumn{4}{|c|}{$\begin{array}{c}\text { OS } 5 \text { years } \\
\text { (death vs. survive) }\end{array}$} \\
\hline & & \multicolumn{2}{|c|}{ Heterogeneity } & \multicolumn{2}{|c|}{$\begin{array}{l}\text { Publication } \\
\text { bias }\end{array}$} & \multicolumn{2}{|c|}{ Heterogeneity } & \multicolumn{2}{|c|}{$\begin{array}{l}\text { Publication } \\
\text { bias }\end{array}$} & \multicolumn{2}{|c|}{ Heterogeneity } & \multicolumn{2}{|c|}{$\begin{array}{l}\text { Publication } \\
\text { bias }\end{array}$} \\
\hline & & $P^{\mathrm{a}}$ & $I^{2}(\%)^{b}$ & $P^{\mathrm{c}}$ & $P^{\mathrm{d}}$ & $P^{\mathrm{a}}$ & $I^{2}(\%)^{b}$ & $P^{\mathrm{c}}$ & $P^{\mathrm{d}}$ & $P^{\mathrm{a}}$ & $I^{2}(\%)^{b}$ & $P^{\mathrm{c}}$ & $P^{\mathrm{d}}$ \\
\hline Over all & & 0.054 & 73 & 1 & NA & 0 & 85.1 & 0.348 & 0.273 & 0 & 75.2 & 0.548 & 0.355 \\
\hline \multicolumn{14}{|l|}{ Cancer type } \\
\hline Larynx & & NA & NA & NA & NA & 0 & 86.2 & 1 & 0.758 & 0.027 & 63.5 & 1 & 0.137 \\
\hline Pharynx & & 0.054 & 73 & 1 & NA & 0.489 & 0 & 1 & NA & 0.001 & 90.8 & 1 & NA \\
\hline \multicolumn{14}{|c|}{ Geographic area } \\
\hline \multirow[t]{3}{*}{ Asia } & over all & NA & NA & NA & NA & 0.01 & 70 & 0.462 & 0.074 & 0.005 & 77 & 1 & 0.798 \\
\hline & Larynx & NA & NA & NA & NA & 0.138 & 45.5 & 1 & 0.328 & 0.059 & 64.7 & 1 & 0.584 \\
\hline & pharynx & NA & NA & NA & NA & NA & 0 & NA & NA & NA & 0 & NA & NA \\
\hline \multirow[t]{3}{*}{ Europe } & over all & NA & NA & NA & NA & 0 & 91.5 & 1 & 0.208 & 0.148 & 47.7 & 0.296 & 0.274 \\
\hline & Larynx & NA & NA & NA & NA & 0 & 92.1 & 1 & 0.509 & 0.674 & 0 & 1 & NA \\
\hline & pharynx & NA & NA & NA & NA & NA & 0 & NA & NA & NA & 0 & NA & NA \\
\hline \multirow[t]{2}{*}{ Larynx } & Pan-CD44 & NA & NA & NA & NA & 0 & 90.7 & 0.806 & 0.901 & 0.026 & 72.5 & 1 & 0.486 \\
\hline & CD44-6 & NA & NA & NA & NA & 0.559 & 0 & 1 & NA & 0.531 & 0 & 1 & NA \\
\hline \multirow{2}{*}{$\begin{array}{l}\text { Larynx \& } \\
\text { pharynx }\end{array}$} & Pan-CD44 & NA & NA & NA & NA & 0 & 88.9 & 1 & 0.712 & 0.001 & 81.4 & 0.308 & 0.145 \\
\hline & CD44-6 & NA & NA & NA & NA & 0.559 & 0 & 1 & NA & 0.531 & 0 & 1 & NA \\
\hline \multirow[t]{2}{*}{ Pharynx } & Pan-CD44 & NA & NA & NA & NA & NA & NA & NA & NA & NA & NA & NA & NA \\
\hline & CD44-6 & NA & NA & NA & NA & NA & NA & NA & NA & NA & NA & NA & NA \\
\hline \multirow[t]{2}{*}{ Sample size ${ }^{a}$} & $<58.5$ & NA & NA & NA & NA & 0.328 & 13 & 0.734 & 0.208 & 0 & 83.4 & 0.734 & 0.454 \\
\hline & $\geq 58.5$ & NA & 0 & NA & NA & 0 & 90.8 & 0.806 & 0.753 & 0.059 & 64.7 & 1 & 0.584 \\
\hline \multirow{2}{*}{$\begin{array}{l}\text { Follow time } \\
\text { (month) }^{\mathrm{b}}\end{array}$} & $<68.5$ & NA & NA & NA & NA & 0 & 89.3 & 0.707 & 0.789 & 0.005 & 77 & 1 & 0.798 \\
\hline & $\geq 68.5$ & NA & 0 & NA & NA & 0.249 & 28 & 1 & 0.363 & 0.148 & 47.7 & 0.296 & 0.274 \\
\hline
\end{tabular}

NA, not available.

a $P$ for heterogeneity within each subgroup.

${ }^{b}$ Proportion of between-study heterogeneity accounting for total heterogeneity.

${ }^{c} P$ values of Begg's test.

d $P$ values of Egger's test.

related with lymph node metastasis ( $\mathrm{N}$ category).

CD44 was first described as a lymphocyte homing receptor in 1983 (Gallatin et al. 1983), and subsequently, its expression was found in various cell types. Extensive evidence showed that CD44 played important roles in tumor progression, especially with cancer stem cell related characteristics. In tumor progression, CD44 was predominantly related to cancer cell invasion and metastasis. Once CD44 interacted with hyaluronan (HA), as an important ligand of CD44, the cytoplasmic tail of CD44 binded to the actin cytoskeleton and induced CD44 movement toward the leading edge of the migrating cells. Thereafter CD44 could bind to CD62 on endothelial cells, resulting in the migrating cells rolling on the endothelial cells as the initial step of the extravasation (Lamontagne and Grandbois 2008; Fehon et al. 2010; Zoller 2011). The HA-CD44 interaction could also activate the ROK pathway, which resulted the phosphorylation of the $\mathrm{Na}+/ \mathrm{H}+$ exchange (Bourguignon et al. 2004) and facilitated extracellular matrix degradation and tumor invasion. These reports demonstrated that CD44 was closely related with lymph node metastasis, which were well supported by our meta-analysis.

CD44s, v3, v5, v6, and v9 have been reported to be expressed in the HNSCC of the head and neck (Piffko et al. 1996; Ue et al. 1998; Rodrigo et al. 2003; Huang et al. 2007; Staibano et al. 2007). Studies have shown the distinct function of specific CD44 isoforms in cancer progression. The epithelial-mesenchymal transition (EMT) process is very critical for cancer metastasis and recurrence, researches has revealed the shift from CD44v to CD44s is essential for the EMT process, and the high expression of CD44s is associated with the aggressive recurrence pattern of hepatocellular carcinoma cells (Brown et al. 2011; Mima et al. 2013). On the other hand, CD44v instead of CD44s, could be stimulated by hypoxia-inducible factor- $1 \alpha$ to promote tumor metastasis (Krishnamachary et al. 2012). The above results suggested that different CD44 isoforms had distinct biological functions in tumor progression. Additional future studies are needed to evaluate the specific prognostic value of different CD44 variants in pharyngo- 
Table 4. Characteristics of antibodies applied.

\begin{tabular}{|c|c|c|c|c|c|}
\hline No & Year & Author & CD44 antibody type & Source of the antibody & $\begin{array}{l}\text { Monoclonal/antibody } \\
\text { (clonal number) }\end{array}$ \\
\hline 1 & 1999 & Song & cd44-v6 & $\begin{array}{l}\text { Commercial } \\
\text { (Maxim, China) }\end{array}$ & Monoclonal (2F10) \\
\hline 2 & 2000 & Wang & pan-cd44 & $\begin{array}{l}\text { Commercial } \\
\text { (R\&D, USA) }\end{array}$ & Monoclonal (2C5) \\
\hline 3 & 2003 & $\mathrm{Xu}$ & cd44-v6 & $\begin{array}{l}\text { Commercial } \\
\text { (Novocastra, UK) }\end{array}$ & Monoclonal (DF1485) \\
\hline 4 & 2003 & Zhao & pan-cd44 & $\begin{array}{l}\text { Commercial } \\
\text { (DAKO, Danmark) }\end{array}$ & Monoclonal (DF1485) \\
\hline 5 & 2004 & Kawano & CD44 standard & $\begin{array}{l}\text { Commercial } \\
\text { (R\&D, USA) }\end{array}$ & Monoclonal (clonal No. not provided) \\
\hline 6 & 2004 & Wang & pan-cd44 & $\begin{array}{l}\text { Commercial } \\
\text { (Santa Cruz, USA) }\end{array}$ & Monoclonal (clonal No. not provided) \\
\hline 7 & 2005 & Esteban & pan-cd44 & $\begin{array}{l}\text { Commercial } \\
\text { (DAKO, Danmark) }\end{array}$ & Monoclonal (DF1485) \\
\hline 8 & 2006 & Qiu & pan-cd44 & $\begin{array}{l}\text { Commercial } \\
\text { (Maxim, China) }\end{array}$ & Monoclonal (DF1485) \\
\hline 9 & 2007 & Staibano & cd44-v6 & $\begin{array}{l}\text { Commercial } \\
\text { (Novocastra, UK) }\end{array}$ & Monoclonal (VFF-7) \\
\hline 10 & 2007 & Huang & cd44-v6 & $\begin{array}{l}\text { Commercial } \\
\text { (ZSGB-Bio, Beijing, China) }\end{array}$ & Monoclonal (VFF-7) \\
\hline 11 & 2008 & $\mathrm{Lu}$ & cd44-v6 & $\begin{array}{l}\text { Commercial } \\
\text { (ZSGB-Bio, Beijing, China) }\end{array}$ & Monoclonal (VFF-7) \\
\hline 12 & 2009 & Gao & cd44-v6 & $\begin{array}{l}\text { Commercial } \\
\text { (ZSGB-Bio, Beijing, China) }\end{array}$ & Monoclonal (VFF-7) \\
\hline 13 & 2009 & Guo & cd44-v6 & $\begin{array}{l}\text { Commercial } \\
\text { (Maxim, China) }\end{array}$ & Monoclonal (2F10) \\
\hline 14 & 2009 & $\mathrm{Ma}$ & cd44-v3 & $\begin{array}{l}\text { Commercial } \\
\text { (ZSGB-Bio, Beijing, China) }\end{array}$ & Monoclonal (3G5) \\
\hline 15 & 2011 & Kokko & pan-cd44 & $\begin{array}{l}\text { Commercial } \\
\text { (DAKO, Danmark) }\end{array}$ & Monoclonal (DF1485) \\
\hline 16 & 2011 & Uwa & pan-cd44 & $\begin{array}{l}\text { Commercial } \\
\text { (R\&D, USA) }\end{array}$ & Monoclonal (2C5) \\
\hline 17 & 2011 & Yuce & pan-cd44 & $\begin{array}{l}\text { Commercial } \\
\text { (Novocastra, UK) }\end{array}$ & Monoclonal (DF1485) \\
\hline 18 & 2011 & $\mathrm{LuSM}$ & pan-cd44 & $\begin{array}{l}\text { Commercial } \\
\text { (Abcam, UK) }\end{array}$ & Monoclonal (clonal No. not provided) \\
\hline 19 & 2012 & Janisiewicz & pan-CD44 & $\begin{array}{l}\text { Commercial } \\
\text { (BD, USA) }\end{array}$ & Monoclonal (G44-26) \\
\hline
\end{tabular}

laryngeal cancer.

All the studies included in this meta-analysis assessed CD44 expression with immunohistochemistry staining method, but it was worth noting that some reports found that the soluble form of CD44 (sCD44) also had a remarkable prognostic value. CD44 cleavage was achieved with a proteolytic enzyme, predominantly ADAM10/17; this enzyme cleaved the soluble extracellular epitope of CD44 to a soluble form (sCD44) (Okamoto et al. 2002; Stamenkovic and $\mathrm{Yu}$ 2009). It has been reported that sCD44 (CD44-v6 or CD44-v5) could be of an independent prognostic value in colorectal and breast cancer patients (Kittl et al. 1997; Yamane et al. 1999; Amirghofran et al. 2008). In head and neck cancer, Franzmann et al. (2007) found that $\mathrm{sCD} 44$ was elevated in oral rinses of the majority of HNSCCs and could be highly distinguished cancer from benign disease. Kawano et al. (2005) showed that the serum levels of sCD44, CD44-v5 and CD44-v6 in pretreatment HNSCC patients were closely associated with the TNM stage and were higher than those in the control group. Two studies showed there was no significant difference neither between the serum levels of sCD44-v6 in HNSCC patients and healthy subjects nor an association with the tumor stage and the TNM stage (Van Hal et al. 1999; Andratschke et al. 2005). This contradiction could be explained by the relative small burden of some pharyngolaryngeal cancers that could not change the systemic sCD44 level. Here we suggested it should be cautious of applying serum sCD44 as a prognostic marker in pharyngolaryngeal cancer.

There were limitations in our meta-analysis. First, most of the included studies were cohort studies, in which 
there were difficulties in controlling the confounders that could affect the valid prognostic value of CD44 expression. Second, $75 \%$ of the studies were performed in Asia, with 2 from Japan and 12 from China. Third, because of the limited information about the CD44 variants in pharyngolaryngeal cancer, our meta-analysis was restricted to analyze the correlations between pan-CD44 and CD44-v6 and patient prognosis. Our systematic review and meta-analysis suggested that high CD44 expression indicated worse $\mathrm{T}$ and $\mathrm{N}$ grades and a shortened OS rate. The association between the specific CD44 variants and the clinicopathological features of pharyngolaryngeal cancer was insufficient, and additional studies are needed to evaluate CD44 as a therapeutic target in cancer treatment.

\section{Acknowledgements}

This work was supported by the Science Technology Department of Zhejiang Province (No. 2012C33105). The funders had no role in study design, data collection and analysis, decision to publish, or preparation of the manuscript.

\section{Conflict of Interest}

The authors declare no conflict of interest.

\section{References}

Amirghofran, Z., Jalali, S.A., Hosseini, S.V., Vasei, M., Sabayan, B. \& Ghaderi, A. (2008) Evaluation of CD44 and CD44v6 in colorectal carcinoma patients: soluble forms in relation to tumor tissue expression and metastasis. J. Gastrointest. Cancer, 39, 73-78.

Andratschke, M., Chaubal, S., Pauli, C., Mack, B., Hagedorn, H. \& Wollenberg, B. (2005) Soluble CD44v6 is not a sensitive tumor marker in patients with head and neck squamous cell cancer. Anticancer Res., 25, 2821-2826.

Bourguignon, L.Y., Singleton, P.A., Diedrich, F., Stern, R. \& Gilad, E. (2004) CD44 interaction with $\mathrm{Na}+-\mathrm{H}+$ exchanger (NHE1) creates acidic microenvironments leading to hyaluronidase-2 and cathepsin B activation and breast tumor cell invasion. $J$. Biol. Chem., 279, 26991-27007.

Brown, R.L., Reinke, L.M., Damerow, M.S., Perez, D., Chodosh, L.A., Yang, J. \& Cheng, C. (2011) CD44 splice isoform switching in human and mouse epithelium is essential for epithelial-mesenchymal transition and breast cancer progression. J. Clin. Invest., 121, 1064-1074.

Esteban, F., Bravo, J.J., Gonzalez-Moles, M.A., Bravo, M., RuizAvila, I. \& Gil-Montoya, J.A. (2005) Adhesion molecule CD44 as a prognostic factor in laryngeal cancer. Anticancer Res., 25, 1115-1121.

Faber, A., Barth, C., Hormann, K., Kassner, S., Schultz, J.D., Sommer, U., Stern-Straeter, J., Thorn, C. \& Goessler, U.R. (2011) CD44 as a stem cell marker in head and neck squamous cell carcinoma. Oncol. Rep., 26, 321-326.

Fehon, R.G., McClatchey, A.I. \& Bretscher, A. (2010) Organizing the cell cortex: the role of ERM proteins. Nat. Rev. Mol. Cell Biol., 11, 276-287.

Fox, S.B., Fawcett, J., Jackson, D.G., Collins, I., Gatter, K.C., Harris, A.L., Gearing, A. \& Simmons, D.L. (1994) Normal human tissues, in addition to some tumors, express multiple different CD44 isoforms. Cancer Res., 54, 4539-4546.

Franzmann, E.J., Reategui, E.P., Pedroso, F., Pernas, F.G., Karakullukcu, B.M., Carraway, K.L., Hamilton, K., Singal, R. \& Goodwin, W.J. (2007) Soluble CD44 is a potential marker for the early detection of head and neck cancer. Cancer
Epidemiol. Biomarkers Prev., 16, 1348-1355.

Gallatin, W.M., Weissman, I.L. \& Butcher, E.C. (1983) A cellsurface molecule involved in organ-specific homing of lymphocytes. Nature, 304, 30-34.

Gao, Y. (2009) The expression and its significance of CD44v6 in human laryngeal and hypopharyngeal squamous cell carcinoma. Chi. Med. Herald, 6, 76-77.

Guo, X., Li, X., Li, F., Feng, S., Li, X., Pan, Z., Guan, C., Wang, Y., Yang, H. \& Jiang, X. (2009) Expression of gene BRMS1 and CD44v6 protein in supraglottic laryngeal carcinoma and its clinical significance. J. Clin. Otorhinolaryngol. Head and Neck Surg. (China), 23, 249-253.

Huang, S., Luo, W., Wu, S., Wang, W. \& Chen, X. (2007) Expression of PCNA and CD44V6 in laryngeal carcinoma. $J$. Guangdong Med. coll., 2, 142-144.

Janisiewicz, A.M., Shin, J.H., Murillo-Sauca, O., Kwok, S., Le, Q.T., Kong, C., Kaplan, M.J. \& Sunwoo, J.B. (2012) CD44(+) cells have cancer stem cell-like properties in nasopharyngeal carcinoma. Int. Forum Allergy Rhinol., 2, 465-470.

Kawano, T., Nakamura, Y., Yanoma, S., Kubota, A., Furukawa, M., Miyagi, Y. \& Tsukuda, M. (2004) Expression of E-cadherin, and CD44s and CD44v6 and its association with prognosis in head and neck cancer. Auris Nasus Larynx, 31, 35-41.

Kawano, T., Yanoma, S., Nakamura, Y., Ozeki, A., Kokatsu, T., Kubota, A., Furukawa, M. \& Tsukuda, M. (2005) Soluble CD44 standard, CD44 variant 5 and CD44 variant 6 and their relation to staging in head and neck cancer. Acta Otolaryngol., 125, 392-397.

Kittl, E.M., Ruckser, R., Selleny, S., Samek, V., Hofmann, J., Huber, K., Reiner, A., Ogris, E., Hinterberger, W. \& Bauer, K. (1997) Evaluation of soluble CD44 splice variant v5 in the diagnosis and follow-up in breast cancer patients. Exp. Clin. Immunogenet., 14, 264-272.

Kokko, L.L., Hurme, S., Maula, S.M., Alanen, K., Grenman, R., Kinnunen, I. \& Ventela, S. (2011) Significance of site-specific prognosis of cancer stem cell marker CD44 in head and neck squamous-cell carcinoma. Oral Oncol., 47, 510-516.

Krishnamachary, B., Penet, M.F., Nimmagadda, S., Mironchik, Y., Raman, V., Solaiyappan, M., Semenza, G.L., Pomper, M.G. \& Bhujwalla, Z.M. (2012) Hypoxia regulates CD44 and its variant isoforms through HIF-1alpha in triple negative breast cancer. PLoS One, 7, e44078.

Lamontagne, C.A. \& Grandbois, M. (2008) PKC-induced stiffening of hyaluronan/CD44 linkage; local force measurements on glioma cells. Exp. Cell Res., 314, 227-236.

Lee, J.H., Kim, S.H., Lee, E.S. \& Kim, Y.S. (2009) CD24 overexpression in cancer development and progression: a meta-analysis. Oncol. Rep., 22, 1149-1156.

Leung, E.L., Fiscus, R.R., Tung, J.W., Tin, V.P., Cheng, L.C., Sihoe, A.D., Fink, L.M., Ma, Y. \& Wong, M.P. (2010) Nonsmall cell lung cancer cells expressing CD44 are enriched for stem cell-like properties. PLoS One, 5, e14062.

Lu, J., Gao, Y., Xiao, Y. \& Jin, D. (2008) Expression and clinical significance of CD44v6 in tissues of laryngeal and hypopharyngeal squamous cell carcinoma. J. Harbin Med. Univ., 42, 142-146.

Lu, S., Tian, J., Lv, Z., Wang, H., Bai, X., Liu, W., Li, J. \& Xu, W. (2011) The probable role of tumor stem cells for lymph node metastasis in supraglottic carcinoma. Pathol. Oncol. Res., 17, 33-38.

Ma, D., Yuan, L., Zhao, Y., Zhou, X., Li, C. \& Liu, L. (2009) Relationship study between KAI1, CD44v3 expressions and laryngeal carcinoma. J. Shandong Med. Coll., 31, 87-90.

Mima, K., Hayashi, H., Imai, K., Kuroki, H., Nakagawa, S., Okabe, H., Chikamoto, A., Watanabe, M., Beppu, T. \& Baba, H. (2013) High CD44s expression is associated with the EMT expression profile and intrahepatic dissemination of hepatocellular carcinoma after local ablation therapy. J. Hepatobiliary Pancreat. Sci., 20, 429-434. 
ML, P. \& O, C. (2010) Clinical Analysis of 2666 Cases of Otothinolaryngologic Tumors. J. Jilin Univ., 13, 57.

Murata, T., Yasuoka, Y., Shimada, T., Shino, M., Iida, H., Takahashi, K. \& Furuya, N. (2011) A new and less invasive procedure for arytenoid adduction surgery: endoscopicassisted arytenoid adduction surgery. Laryngoscope, 121, 1274-1280.

Nguyen, L.V., Vanner, R., Dirks, P. \& Eaves, C.J. (2012) Cancer stem cells: an evolving concept. Nat. Rev. Cancer, 12, 133-143.

Ni, C., Zhang, Z., Zhu, X., Liu, Y., Qu, D., Wu, P., Huang, J. \& Xu, A.X. (2013) Prognostic value of CD166 expression in cancers of the digestive system: a systematic review and meta-analysis. PLoS One, 8, e70958.

Okamoto, I., Tsuiki, H., Kenyon, L.C., Godwin, A.K., Emlet, D.R., Holgado-Madruga, M., Lanham, I.S., Joynes, C.J., Vo, K.T., Guha, A., Matsumoto, M., Ushio, Y., Saya, H. \& Wong, A.J. (2002) Proteolytic cleavage of the CD44 adhesion molecule in multiple human tumors. Am. J. Pathol., 160, 441-447.

Piffko, J., Bankfalvi, A., Klauke, K., Dreier, R., Joos, U., Bocker, W. \& Schmid, K.W. (1996) Unaltered strong immunohistochemical expression of CD44-v6 and -v5 isoforms during development and progression of oral squamous cell carcinomas. J. Oral Pathol. Med., 25, 502-506.

Qiu, X., Huang, J., Zhang, Z., Da, P. \& Zhou, R. (2006) The expression of CD44 and its clinical significance in human laryngeal carcinoma. Med. J. Commun., 20, 670-671.

Rodrigo, J.P., Dominguez, F., Alvarez, C., Gonzalez, M.V., Herrero, A. \& Suarez, C. (2002) Clinicopathologic significance of expression of CD44s and CD44v6 isoforms in squamous cell carcinoma of the supraglottic larynx. Am. J. Clin. Pathol., 118, 67-72.

Rodrigo, J.P., Dominguez, F., Alvarez, C., Herrero, A. \& Suarez, C. (2003) Expression of E-cadherin, CD44s, and CD44v6 in laryngeal and pharyngeal carcinomas. Am. J. Otolaryngol., 24, 384-389.

Siegel, R., Naishadham, D. \& Jemal, A. (2012) Cancer statistics, 2012. CA Cancer J. Clin., 62, 10-29.

Song, X., Peng, J., Cai, X., Hou, F. \& Lin, Q. (1999) Expression of CD44v6 protein in laryngeal squamous cell carcinoma. Chi. J. Otorhinolaryngology-Skull Base Surg., 5, 76-79.

Staibano, S., Merolla, F., Testa, D., Iovine, R., Mascolo, M., Guarino, V., Castellone, M.D., Di Benedetto, M., Galli, V., Motta, S., Melillo, R.M., De Rosa, G., Santoro, M. \& Celetti, A. (2007) OPN/CD44v6 overexpression in laryngeal dysplasia and correlation with clinical outcome. Br. J. Cancer, 97, 1545-1551.

Stamenkovic, I. \& Yu, Q. (2009) Shedding light on proteolytic cleavage of CD44: the responsible sheddase and functional significance of shedding. J. Invest. Dermatol., 129, 13211324.

Stroup, D.F., Berlin, J.A., Morton, S.C., Olkin, I., Williamson, G.D., Rennie, D., Moher, D., Becker, B.J., Sipe, T.A. \& Thacker, S.B. (2000) Meta-analysis of observational studies in epidemiology: a proposal for reporting. Meta-analysis Of Observational Studies in Epidemiology (MOOSE) group.
JAMA, 283, 2008-2012.

Su, Y.J., Lai, H.M., Chang, Y.W., Chen, G.Y. \& Lee, J.L. (2011) Direct reprogramming of stem cell properties in colon cancer cells by CD44. EMBO J., 30, 3186-3199.

Ue, T., Yokozaki, H., Kagai, K., Higashikawa, K., Yasui, W., Sugiyama, M., Tahara, E. \& Ishikawa, T. (1998) Reduced expression of the CD44 variant exons in oral squamous cell carcinoma and its relationship to metastasis. J. Oral Pathol. Med., 27, 197-201.

Uwa, N., Kataoka, T.R., Torii, I., Sato, A., Nishigami, T., Song, M., Daimon, T., Saeki, N., Sagawa, K., Mouri, T., Terada, T., Sakagami, M. \& Tsujimura, T. (2011) CD44 expression is related to poor prognosis of hypopharyngeal squamous cell carcinoma. Acta Otolaryngol., 131, 323-329.

van der Windt, G.J., Schouten, M., Zeerleder, S., Florquin, S. \& van der Poll, T. (2011) CD44 is protective during hyperoxiainduced lung injury. Am. J. Respir. Cell Mol. Biol., 44, 377-383.

Van Hal, N.L., Van Dongen, G.A., Ten Brink, C.B., Heider, K.H., Rech-Weichselbraun, I., Snow, G.B. \& Brakenhoff, R.H. (1999) Evaluation of soluble CD44v6 as a potential serum marker for head and neck squamous cell carcinoma. Clin. Cancer Res., 5, 3534-3541.

Wang, K., Xu, J., Zhang, J. \& Huang, J. (2012) Prognostic role of CD133 expression in colorectal cancer: a meta-analysis. $B M C$ Cancer, 12, 573.

Wang, M., Xing, L. \& Zhang, C. (2004) Study in the expression of CD44 in nasopharyngeal neoplasms and the clinical relationship. Tianjin Med. J., 32, 535-537.

Wang, S.L., Yang, Q., Xiao, B.K., Jiang, Y.S. \& Chen, E.H. (2000) Expression of CD44s and CD44v6 in laryngeal squamous cell carcinoma and their significance. J. Clin. Otorhinolaryngol (China), 14, 446-448.

Xu, Y.P., Zhao, X.Q., Sommer, K. \& Moubayed, P. (2003) Correlation of matrix metalloproteinase-2, -9, tissue inhibitor-1 of matrix metalloproteinase and CD44 variant 6 in head and neck cancer metastasis. J. Zhejiang Univ. Sci., 4, 491-501.

Yamane, N., Tsujitani, S., Makino, M., Maeta, M. \& Kaibara, N. (1999) Soluble CD44 variant 6 as a prognostic indicator in patients with colorectal cancer. Oncology, 56, 232-238.

Yuce, I., Bayram, A., Cagli, S., Canoz, O., Bayram, S. \& Guney, E. (2011) The role of CD44 and matrix metalloproteinase-9 expression in predicting neck metastasis of supraglottic laryngeal carcinoma. Am. J. Otolaryngol., 32, 141-146.

Zhao, S., Sun, B., He, J., Ye, Q., Lin, S. \& Sun, A. (2003) The expression of CD44 and its significance in human laryngeal carcinoma. J. Clin. Otorhinolaryngol. (China), 17, 164-166.

Zhu, J., Fedewa, S. \& Chen, A.Y. (2012) The impact of comorbidity on treatment (chemoradiation and laryngectomy) of advanced, nondistant metastatic laryngeal cancer: a review of 16849 cases from the national cancer database (2003-2008). Arch. Otolaryngol. Head Neck Surg., 138, 1120-1128.

Zoller, M. (2011) CD44: can a cancer-initiating cell profit from an abundantly expressed molecule? Nat. Rev. Cancer, 11, 254-267. 